\title{
STRESS INDICATOR FOR CLEARING HOUSES
}

\section{Berlinger, E., Dömötör, B., Illés, F., Váradi, K.}

As a regulatory answer to the crisis, financial instruments are increasingly forced to be cleared centrally even in the OTC markets; therefore, risk management of central clearinghouses has become a central issue. A key term of the regulation is a stress event; however, it is not specified in the legislation what should be meant under stress in the case of a clearinghouse. To find an objective stress indicator, we built up a micro-simulation model of a hypothetical clearinghouse operating on the US equity market between 2007 and 2015. Based on this, we developed a logit regression model to specify an appropriate stress indicator and we showed that our "tailor-made" stress index calibrated to the position of the clearinghouse performs significantly better than the usual market proxies for financial stress.

Keywords: Financial stability; central counterparty; EMIR; agent-based simulation; logit regression; Gini-coefficient

JEL Classification: G01, G23, G32

\section{Introduction}

As a regulatory answer to the crisis, a new regulation of central clearing came into force to enhance the stability and transparency of the financial system. The new regulation accepted by the United States Congress (Dodd-Frank Act) (Library of Congress, 2010) and also by the European Commission (2012) (European Market Infrastructure Regulation, EMIR) stipulates all standardized OTC transactions between major market participants be cleared centrally by a regulated Central Counterparty (CCP) (Duffie and Zhu, 2011).

In the literature of central clearing, there is a fierce debate on its systemic effects from a macroeconomic perspective. There are two main arguments supporting the idea of central clearing: the increasing transparency and the significant reduction in the overall exposure of market participants (Kiff et al. 2009, 2010; Cont and Kokholm, 2014). However, the efficiency of centralizing the clearing activity also depends on the micro level stability of CCPS. To avoid that too-big-to-fail banks are solely replaced by too-bigto-fail CCPs, CCPs should be subject to prudent risk management procedures and be effectively regulated and supervised (Kiff et al., 2010). Some authors emphasized the importance of keeping CCPs away from more complex financial activities, as well (Hull, 2015). Heller and Vause (2012) and Duffie et al. (2015) analyzed the effects of central clearing on the collaterals' level and they investigated the liquidity risks of the clearing members based on real market data of OTC exposures, while Barker et al. (2016) built a simulation model to capture the complexity of credit and liquidity risks CCP members are facing.

Our research relates to a very special element of the implementation of European regulation of the central clearing (EMIR) which determines the process of CCPs' risk management in many details; but gives freedom to the institutions to define a stress event 
which plays an important role from two aspects: (i) in the case of a stress situation, institutions get more autonomy to react flexibly to the crisis (e.g. the anticyclical buffer can be released); (ii) risk models are required to incorporate the experience of real stress periods in the framework of stress tests, scenario analysis, and model calculations.

When defining a stress event, CCPs may apply basically two different approaches: (i) it can be based on experts' opinion for example by a risk management committee and approved by the regulator time to time; or (ii) it can be predefined in an objective way. In the latter case, the criteria can be endogenous corresponding to the risk management system of the clearinghouse (e.g. oversteps of Value-at-Risk or other risk measure, margin calls, non-repayments after margin calls, call-downs of the cross-guarantee fund), or exogenous. Exogenous stress definitions can rely on (i) a prefabricated "ready-made" general financial stress index calculated by a third player (regulator or other agencies); or (ii) a self-manufactured stress index tailor-made to the special needs of the clearinghouse.

In this paper, we argue that self-made models calibrated to the clearinghouse data perform better in identifying stress events than universal financial stress indices as the latter ones do not necessary take into consideration the special features of the clearing industry. We present a logit regression model which provides a natural stress indicator as an output ranging between 0 and 1 , where a larger value indicates a deeper crisis.

In Section 2, we build a microsimulation model of central clearing in general and analyze the potential losses that could have derived from the trading on the US equity futures market between 2007 and 2015. In Section 3, we regress these losses against some market proxies of financial stress and based on this, we suggest a tailor-made stress indicator. In Section 4, we derive conclusions.

\section{Microsimulation}

CCPs operate a multistage, so-called "waterfall" risk management framework that acts to absorb the losses deriving from the default of the trading partners. The first level of this framework is the margin account of the defaulting client, the insufficiency of which activates the second level, i. e. the cross-guarantee system among all the clients, and finally, the last level is the own fund of the CCP.

In our analysis, we focus only on the first level losses, because the primary goal of CCPs' risk management is the reduction of these losses as much as possible to save higher level guarantee funds. As historical data on the losses of real world clearinghouses are not publicly available, we turn to microsimulation techniques.

The risk management of a clearinghouse shows lots of similarities with risk management in banks, mutual funds or other financial institutions. For example, the calculation of the required margin levels in a clearinghouse relies basically on the same concepts than the calculation of the regulatory capital in a bank using the most popular risk measures, like Value-at-Risk (VaR) and Expected Shortfall (ES) which are complemented with other widely used methods such as stress test and scenario analysis. However, the activity of central counterparties is quite different from that of other financial institutions in many respects. Firstly, clearinghouses are highly specialized institutions having only one well-defined task: managing partner risk in some market segments. This one-task-one-organization setting makes the operation much less liable to conflicts of interests, which increases transparency and responsibility. Secondly, clearinghouses hold short and long positions approximately of equal weights; therefore, stress is a more symmetric concept 
given that a sudden upward price movement can also impose significant partner risk. As they hold a neutral position, their net exposure to risk factors is around zero; thus, contrary to banks and mutual funds holding long overall positions, they are not directly interested in the long-term asset returns. Thirdly, clearinghouses operate a sophisticated margin account system with a daily settlement. If clients do not take off all the accumulated profits in line with favorable market trends, collaterals can be significantly higher than officially required which makes the operation of the clearinghouse safer but path-dependent at the same time. It is also worth mentioning that clearinghouses can dynamically hedge partner risk by changing margin requirements on a daily basis; therefore, they have a more active role in the case of a stress situation. All of these features are included in our model.

One important distinctive feature of our model is that the positions of the CCP come from the simulation of the trades; hence its risk exposure is determined endogenously by modeling the clients' trading activity which is influenced by the overall market conditions. In the other models found in the literature, e.g. Duffie et al., (2015), Heller and Vause (2012), and Barker et al. (2016), the clearinghouse's positions are given exogenously.

Microsimulation is a flexible tool which provides a large scale of freedom; however, the modeler has to keep it as simple as possible, focusing on the research question under investigation (O’Donoghue, 2001).

\subsection{The Model}

The number of traded stocks is $M$. Let $S_{t}^{m}$ denote the closing spot price of stock $m$ at day $t$. Stocks are traded also on futures markets with expirations in the next two Decembers. Expiration dates are denoted by $T_{k}$ where $k=1$ or 2 .

For the sake of simplicity, the clearinghouse is active exclusively on stock futures markets. ${ }^{1}$ Futures prices are determined according to the no-arbitrage principle:

$$
F_{t}^{m, k}=S_{t}^{m} \cdot(1+r)^{T_{k}-t}
$$

where $r$ stands for the risk-free rate which is supposed to be constant. The number of potential traders belonging to the given clearinghouse is $N$. Traders are uninformed; hence they trade randomly, and therefore trades are independent of prices. Prices are also supposed to be independent of trades as the market covered by the clearinghouse is only a small segment of the global market, therefore, the clearinghouse's activity has no impact on the market prices. All traders are price takers, and trade at the closing price of the day.

In the market of a given stock $m$, the total number of trades within a day $\left(D_{t}^{m}\right)$ is a stochastic variable following a binomial distribution. ${ }^{2}$ The amount of a trade $\left(A_{t}^{m}\right)$ (i.e. the number of stocks involved in a trade) also follows a binomial distribution. ${ }^{3}$ The mean and the standard deviation of the number and the amount of trade are set arbitrarily.

1 Spot markets are operating on a $t+2$ days basis, so they can be regarded as special futures markets of very short expiration.

2 If there are $N$ uniform traders who decide to trade on a given day with probability $p$, then the number of trades will follow a binomial distribution, hence this is a simplifying but realistic assumption.

3 The distribution of trading volume on financial markets is not exhibiting "fat tail" characteristics because traders avoid extreme large trades by cutting their orders into smaller units to minimize the price impact, and they also avoid too small trades because of the fixed transactional costs (Lo and Wang, 2009). According to Camargo et al. (2013), the trading volume's distribution can be best approximated by a lognormal one, and this can be replaced by a binomial distribution in the discrete case. 
A trade is made between trader $i$ (long side) and trader $j$ (short side), where $i, j=1$, $\ldots, N$ and $i \neq j$. Pairs $i, j$ are selected randomly and all traders have an equal chance to be selected. The expiration date of the trade can be $T_{1}$ or $T_{2}$. The probability of the first delivery date is $p_{t}$, and is a decreasing function of the time remaining until $T_{1}$. (As a consequence, $1-p_{t}$ is the probability of the second delivery date.)

We define $A_{(t, d)}^{(m, k)}$ as the trade amount in the $d$-th trade $\left(d=1, \ldots, D_{t}^{m}\right)$ on day $t$ in the market of stock $m$ at delivery date $k$. The position $(P)$ of the $n$-th trader will change accordingly:

$$
\begin{gathered}
\text { if } n=i \text {, then } P_{t, d}^{n, m, k}=A_{t, d}^{m, k} \\
\text { if } n=j \text {, then } P_{t, d}^{n, m, k}=-A_{t, d}^{m, k} \\
\text { otherwise } P_{t, d}^{n, m, k}=0
\end{gathered}
$$

Having simulated numerous trades with different attributes (stock, long and short side traders, trade amount, and delivery date), we can determine the net accumulated exposure $(E)$ of the $n$th trader in stock $m$, on day $t$, for delivery date $k$ as

$$
\begin{gathered}
E_{t}^{n, m, k}=E_{t-1}^{n, m, k}+\sum_{d=1}^{D_{t}^{m}} P_{t, d}^{n, m, k} \\
E_{0}^{n, m, k}=0
\end{gathered}
$$

In this way, positions of opposite signs are canceled out as long and short positions naturally offset each other.

The margin account $(C)$ of the $n$-th trader at the end of the $t$-th day is the sum of the margins across all stocks and expiration dates, and it changes in line with the daily settlement:

$$
\begin{gathered}
C_{t}^{n}=C_{t-1}^{n}-T_{t}+\sum_{m=1}^{M} \sum_{k=1}^{2} E_{t}^{n, m, k} \cdot\left(F_{t}^{m, k}-F_{t-1}^{m, k}\right) \\
C_{0}^{n}=R_{0}^{n}
\end{gathered}
$$

where $T_{t}$ is the profit taken from the account on day $t$.

The margin requirement $(R)$ of the $n$-th trader is calculated at the end of the $t$-th day and is valid for the next day. It is defined as the value-at-risk $(\operatorname{VaR})$ of his/her total portfolio $E_{t}^{n}$ where the data window is $w=1$ year, the holding period is $\tau=1$ day and the significance level is $\alpha=99 \%$.

$$
R_{t}^{n}=\operatorname{VaR}\left(E_{t}^{n}, w, \tau, \alpha\right)
$$

The VaR of the portfolio is calculated using a historic approach. We supposed that there is no extra requirement above this measure.

If the margin account of trader $n$ is less than the requirement, the clearinghouse sends a margin call and asks to refill the margin account up to the required level. It is possible that the trader does not obey the margin call. To make the model sensitive and prudent, the probability of non-repayment $(q)$ is set to 1 . In this case, the clearinghouse closes the position at the next day's closing price.

The first level loss of the clearinghouse $(L)$ on the $t$-th day is defined as the sum of the expected losses on each trader: 


$$
L_{t}=\sum_{n=1}^{N} L_{t}^{n}=-\sum_{n=1}^{N} q_{t}^{n} \cdot \min \left(C_{t}^{n}+E_{t}^{n, m, k} \cdot\left(F_{t}^{m, k}-F_{t-1}^{m, k}\right) ; 0\right)
$$

In the next section, we examine how tendencies in the US stock market would have influenced the position of this hypothetical clearinghouse, and we compare the timing and the magnitude of the losses to some proxies for market stress.

\subsection{The Losses of the Clearing House}

We simulated the operation of a hypothetical clearinghouse described in the previous chapter on the US stock market between 2007 and 2015. The clearinghouse can operate under two regimes: (i) traders leave all their accumulated profits on their account (take nothing); or (ii) traders take off all the profits immediately (take all). Of course, the real world practice lies somewhere between these two extremities; hence, in reality, the size of the collateral and the losses are path-dependent to some extent. ${ }^{4}$

Depending on the actual exposures which are the results of the stochastic trading activity of uninformed traders, we got 100 different paths for the 8-year long period. For each path, a loss/exposure ratio was calculated with daily frequency, where the loss is expressed in dollars, while the exposure is the number of open contracts. Figure 1 shows the average loss/exposure ratios for the 8-year long period under "take nothing" and "take all" regimes.

\section{Figure 1 | Loss/Exposure ratio of a hypothetical clearinghouse on the US stock market}

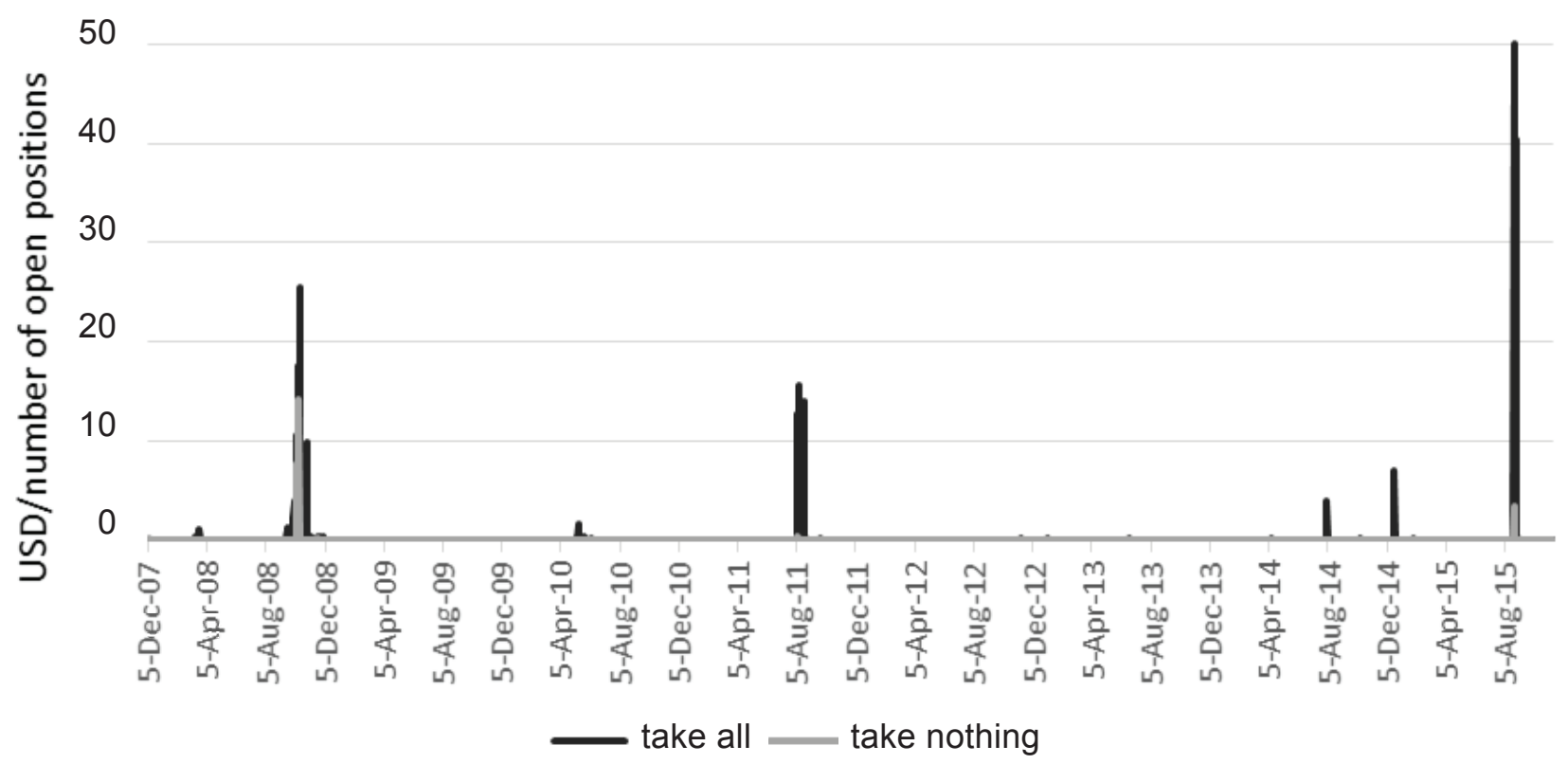

As expected, the size of the losses is much higher in the case of the "take all" regime, but the timing of the losses is the same under the two regimes. We can also observe in Figure 1 that in the recent 8 years, there were approximately 7 significant stress events. Based on the days when the loss to exposure ratio was significantly greater than usual, we found seven periods that can be considered as stress situations in the life of our hypothetical clearinghouse. Dates and the most likely reasons behind are listed here:

4 In the case of OTC derivatives, the profits and losses are typically not settled daily, which meets the "take nothing" regime. 
1. $19-20^{\text {th }}$ March 2008: premonitory signs of the subprime crisis

2. September-October 2008: bankruptcy of Lehman Brothers

3. 11 $11^{\text {th }}$ May 2010: "flash crash" due to high-frequency trading

4. 5-19 $9^{\text {th }}$ August 2011: escalating sovereign debt crisis in the European countries and downgrading of the US credit rating

5. $\quad 1^{\text {st }}$ August 2014: rising geopolitical fears (Ukraine versus Russia, US versus ISIS etc.) and a sell-off in the high-yield debt market

6. $19^{\text {th }}$ December 2014: Russian crash

7. 21-27 $7^{\text {th }}$ August 2015: Chinese crash

As we can see, the most significant crises were due to the Lehman-fall (2008), the European debt crisis (2011) and lately the Chinese crash (2015).

\section{Stress Indicators}

In this part, we analyze the performance of the different - ready-made and tailor-made stress indicators in explaining the losses of the clearinghouse.

\section{1 "Ready-made" Stress Indices}

It is a natural idea to formulate an exact and exogenous definition of clearinghouses' stress event upon a prefabricated general financial stress index. Several financial stress indicators are suggested in the literature, e.g. the Kansas City Financial Stress Index (KCFSI) of Hakkio and Keeton (2009); Financial Stress Indicator of Canada (FSI) by Illing and Liu (2006). These indices all aim to capture overall market stresses. Besides them, there exist some indicators focusing only on a certain feature of stress situations, for example measures expressing the changing risk appetite of investors (Kumar and Persaud, 2001), or measures focusing on a single market segment's stress, for example the stress of the banking sector (Carlson et al. 2008).

In this analysis, we used the Cleveland Financial Stress Index (CFSI), as an exogenous stress index. Like other general indices aggregating trends in different markets, the CFSI takes components that quantify several aspects of the financial system and combines them into a single value. Specifically, the CFSI is constructed using daily data reflecting four financial sectors: credit markets, equity markets, foreign exchange markets, and interbank markets.

\subsection{Toward a Self-Manufactured "Tailor-made" Stress Index}

To create a more efficient, tailor-made stress index, especially for the purposes of our clearinghouse, it is worth examining the market factors that are usually considered as proxies for financial stress, representing market trends, uncertainty and risk appetite of the investors, funding liquidity, and market liquidity. Extreme price movements in both directions can be caused by turbulence in the market which can be captured by the log return $(y)$, the logarithmic change of the daily prices of $S \& P$ representing market trends. Introduced in 1993 by CBOE, the volatility index (VIX) became a key measure of market expectations of near-term volatility conveyed by S\&P 500 stock index option prices. VIX 
is quoted at a daily basis; many investors consider it as the world's premier barometer of expected uncertainty and investor sentiment. The difference of LIBOR, the London Interbank Offered Rate (LIBOR) and the Overnight Indexed Swap (OIS) is considered to reflect the credit risk on the debt market. LIBOR is a rate of unsecured lending, while OIS, being a swap, is practically free of partner risk as the principal is not exchanged. The spread is generally near to zero under normal market circumstances, but in a crisis, it can jump to a high level reflecting the unavailability of funding. The difference between the best bid and best offer prices is considered to be a good measure of market liquidity. In a theoretical frictionless market, the spread is zero.

Based on these market proxies of financial stress, we set up a logit regression model to quantify to what extent the simulated clearinghouse losses can be explained by the different stress indicators. We developed 5 regression models; the results are detailed in the appendix. Table 1 summarizes the goodness of the 5 different stress indicators, measured by the GINI-coefficients.

Table 1 | GINI coefficients of the different models

\begin{tabular}{|l|l|c|c|}
\hline & \multicolumn{1}{|c|}{ Explanatory variable } & $\begin{array}{c}\text { A) „take all” } \\
\text { regime }\end{array}$ & $\begin{array}{c}\text { B)“take nothing” } \\
\text { regime }\end{array}$ \\
\hline Model 1 & Cleveland Financial Stress Index & 0.3307 & 0.4068 \\
\hline Model 2 & CFSI Equity Contributor & 0.3516 & 0.4445 \\
\hline Model 3 & Log return & 0.1115 & 0.2001 \\
\hline Model 4 & Abs log return & 0.7014 & 0.345 \\
\hline Model 5 & $\begin{array}{l}\text { Abs log return, VIX-index, Libor 3M, } \\
\text { OIS, S\&P spread }\end{array}$ & 0.7587 & 0.6193 \\
\hline
\end{tabular}

Source: authors

Model 1 - has Gini coefficients of 0.33 and 0.41 , therefore its explanatory power can be considered as moderate. Interestingly, in the case of the less direct, path-dependent "take-nothing" regime the model performed slightly better.

As our virtual clearinghouse's activity concentrates on the equity market, it is worth focusing on the equity component of the CFSI (called equity contributor: Stock Market Crashes) and analyzing whether it has a higher explanatory power in itself or not.

As expected, specialized Model 2 performed better than general Model 1, but the improvement is not essential. It is not surprising that an equity market stress index suits better to risk profile of a clearinghouse which is active solely on this market.

It is expected that the log return can be the most correlated with the clearinghouse's losses, so in Model 3 the explanatory power of the log return was tested. Unfortunately, the performance of the model is poor, Gini coefficients dropped significantly relative to Model 2. Moreover, we found an S-shape of the ROC curve reflecting that the dependent variable may not be a monotone function of the log returns. Given that clearinghouse losses are rather dependent on the size of the price changes, but not on its direction (due to their symmetric exposures), in Model 4 the explanatory variable is changed to the 
absolute value of log returns. Due to the transformation of the explanatory variable to abs $\log$ return, the Gini coefficient has improved significantly, especially under the "take all" regime, which highlights the strong relationship between the size of actual price changes and the clearinghouse's losses. We have to notice, however, that it is not the size of the price change that matters most, but rather its surprise element that was not incorporated during the calculation of the margin requirement. We can also observe that under the "take nothing" regime the past price movements also counteract in the evolution of the collateral, hence losses are determined not only by the actual price changes but also by the recent ones. This can be the reason why the performance of Model 4 is much weaker in this scenario.

We also tested whether the model can be developed by introducing other stress-related market factors. In Model 5 we incorporated all the above-listed proxies.

We can see that by far this is the best model among those we investigated. It is especially true for the "take all" regime (Gini coefficient=0.76); whilst the "take nothing" regime is also relatively less backward than in Model 4 (Gini coefficient=0.62). All explanatory variables are significant at the $99.9 \%$ level, except for the LIBOR, which has a significance of $99 \%$ under both regimes. The logit regression model provides information on how to create an optimal indicator from these explanatory variables. The estimated stress probability can be considered as a stress indicator ranging between 0 and 1 and its actual value can be calculated according to the formula of regime A in Model 5:

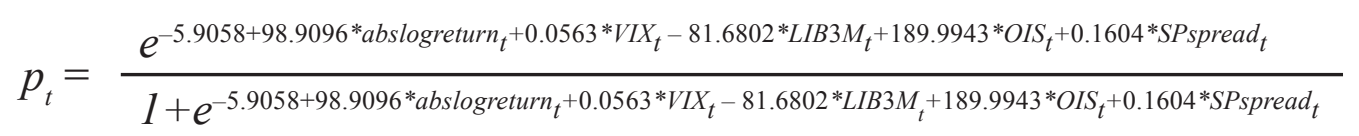

where the index $t$ stands for the date and the explanatory variables are shown in Table 1 . Of course, each institution can build up its own regression model calibrated to its own historical losses and can decide which level of $p$ is regarded as a threshold for stress.

In the case of multivariable regression models, like Model 5, multicollinearity between the explanatory variables can be a critical issue which makes the model less robust, thus less reliable. This problem can be managed for example by increasing the number of observations. Hence, Model 5 serves a promising starting point to create a well-suited tailor-made alert system to be used for defining stress in the case of a particular clearinghouse.

\section{Conclusions}

We investigated a micro-level risk management issue of clearinghouses, namely how to define financial stress for such an institution. We simulated a hypothetical clearinghouse assuming that exposures were built up from random trading activities between 2007 and 2015 in the US futures stock market. With the help of the simulation, we identified seven stress situations over this period, characterized them in terms of their size and timing, and examined the relationship between the losses of the simulated clearinghouse and a readymade stress index (CFSI) available for the US economy. We have found that the link between the vulnerability of our clearinghouse and this general stress index was moderate. Hence, we concluded that this index is not the best choice to build an alert system on and it is better to replace the ready-made composite stress index with independent stress proxies and introduce them into a multivariate logit regression model. 
After some trials and errors, we arrived at a tailor-made multivariate model (Model 5) which performed much better both under the "take all" and "take nothing" regimes. Not surprisingly, the most important explanatory variable is the log return, but due to the symmetric nature of the clearinghouse exposures, we have to take its absolute value. Although our model used similar market proxies as overall market stress indices, we could see that entering the elements separately helps in exploiting more information and provides a better prediction than using the composite index as a single explanatory variable.

Based on our results, we propose to develop an objective stress indicator calibrated to the special needs of the given clearinghouse, because general stress indices do not take into consideration the special features of the clearing industry (monopolistic position, high specialization, symmetric and balanced exposures, path dependency of margin accounts, and dynamic risk management tools).

\section{References}

Barker, R., Dickinson, A., Lipton, A., \& Virmani, R. (2016). Systemic Risks in CCP Networks. arXiv preprint arXiv:1604.00254.

Camargo, S., Queirós, S. M. D., \& Anteneodo, C. (2013). Bridging stylized facts in finance and data non-stationarities. European Physical Journal B, 86(159), 1-13.

Carlson, M. A., Thomas B. K., \& Lewis, K. F. (2008). Distress in the Financial Sector and Economic Activity. Federal Reserve Board. Finance and Economics Discussion Series No. 2008-43.

Cont, R., \& Kokholm, T. (2014). Central Clearing of OTC Derivatives: bilateral and multilateral netting. Statistics \& Risk Modeling, 31(1), 3-22.

Duffie, D., \& Zhu, H. (2011). Does a central clearing counterparty reduce counterparty risk? Review of Asset Pricing Studies, 1(1), 74-95.

Duffie, D., Scheicher, M., \& Vuillemey, G. (2015). Central clearing and collateral demand. Journal of Financial Economics, 116(2), 237-256.

European Commission (2012). Regulation (EU) No 648/2012 of the European Parliament and of the Council of 4 July 2012, on OTC derivatives, central counterparties and trade repositories. Retrieved January 2, 2017 from http://eur-lex.europa.eu/LexUriServ/ LexUriServ.do?uri=OJ:L:2012:201:0001:0059:EN:PDF

Hakkio, C. S., \& Keeton, W. R. (2009). Financial stress: what is it, how can it be measured, and why does it matter? Economic Review, 94(2), 5-50.

Heller, D., \& Vause, N. (2012). Collateral requirements for mandatory central clearing of overthe-counter derivatives. BIS Working Paper No. 373.

Hull, J. C. (2015). Risk Management and Financial Institutions. New York: John Wiley \& Sons.

Illing, M., \& Liu, Y. (2006). Measuring financial stress in a developed country: An application to Canada. Journal of Financial Stability, 2(3), 243-265.

Kiff, J., Elliott, J., Kazarian, E., Scarlata, Jodi, \& Spackman, C. (2009). Credit Derivatives: Systemic Risks and Policy Options. IMF Working Paper 09/254.

Kiff, J., Dodd, R., Gullo, A., Kazarian, E., Lustgarten, I., Sampic, C., \& Singh, M. (2010). Making Over-the-Counter Derivatives Safer: The Role of Central Counterparties. Global Financial Stability Report, IMF. 
Kumar, M. S., \& Persaud, A. (2001). Pure Contagion and Investors' Shifting Risk Appetite; Analytical Issues and Empirical Evidence. IMF Working Paper No. 01-134.

Library of Congress (2010). Dodd-Frank Wall Street Reform and Consumer Protection Act: Public Law 111-203 July 21st 2010. Library of Congress [online]. Retrieved January 2, 2017 from https://www.congress.gov/111/plaws/publ203/PLAW-111 publ203.pdf

Lo, A. W., \& Wang, J. (2009). Stock Market Trading Volume. in Y. Ait-Sahalia and L. Hansen, eds., The Handbook of Financial Econometrics. New York: North-Holland.

O’Donoghue, C. (2001). Dynamic Microsimulation: A Methodological Survey. Brazilian Electronic Journal of Economics, 4, 1-77.

\section{Authors}

Dr. Edina Berlinger

Associate Professor

Corvinus University of Budapest

Fővám tér 8

H-1165, Budapest, Hungary

edina.berlinger@uni-corvinus.hu

\section{Dr. Barbara Dömötör}

Adjunct Professor

Corvinus University of Budapest

Fővám tér 8

H-1165, Budapest, Hungary

barbara.dömötör@uni-corvinus.hu

\section{Ferenc Illés}

PhD Student

Corvinus University of Budapest

Fővám tér 8

H-1165, Budapest, Hungary

illesf16@gmail.com

\section{Dr. Kata Váradi}

Associate Professor

Corvinus University of Budapest

Fővám tér 8

H-1165, Budapest, Hungary

kata.varadi@uni-corvinus.hu

This paper was supported by the János Bolyai Research Scholarship of the Hungarian Academy of Sciences. 


\section{Appendix}

\section{Outputs of Model 1}

(explanatory variable: Cleveland Financial Stress Index)

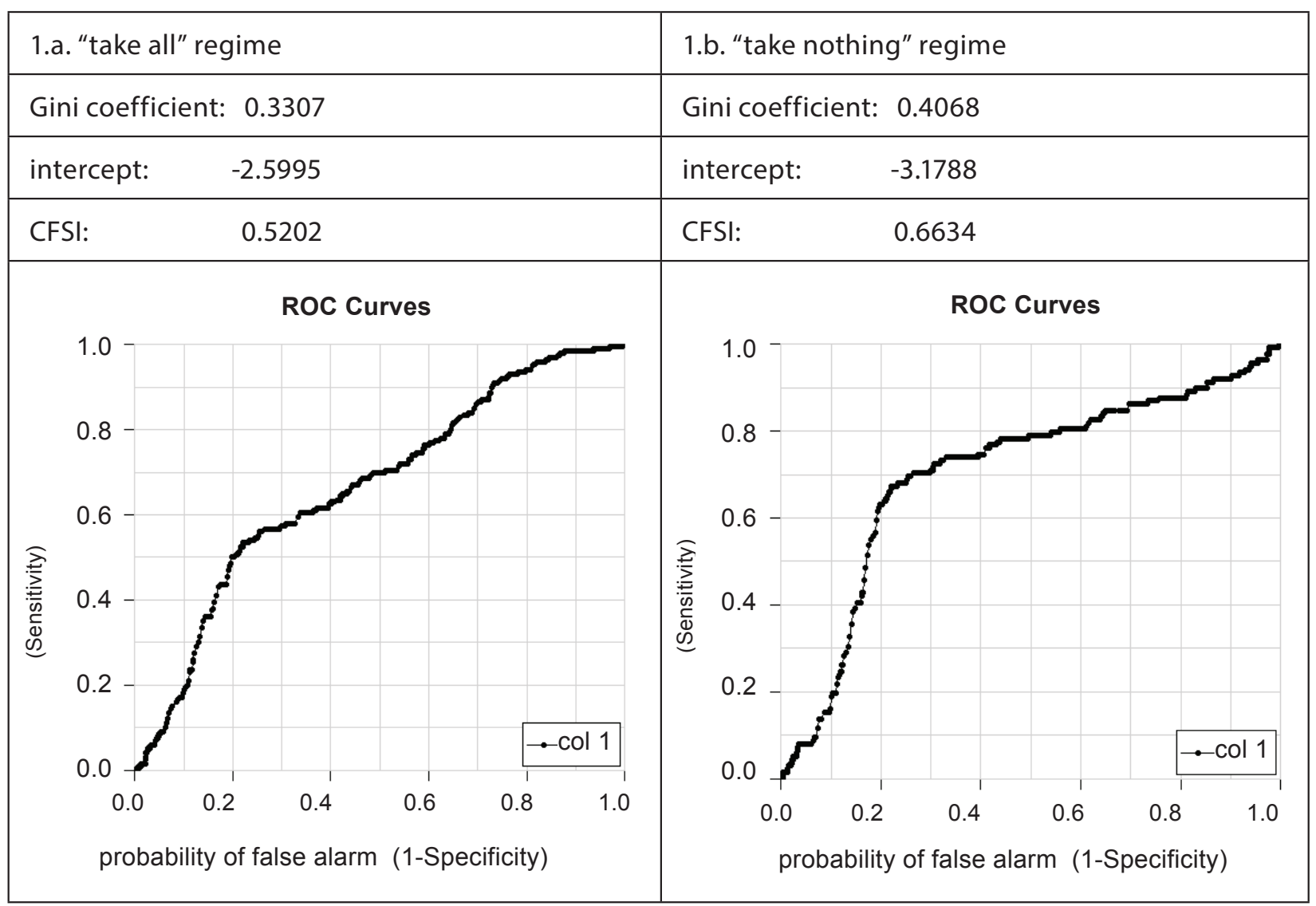

Source: the authors 
Outputs of Model 2

(explanatory variable: CFSI Equity Contributor)

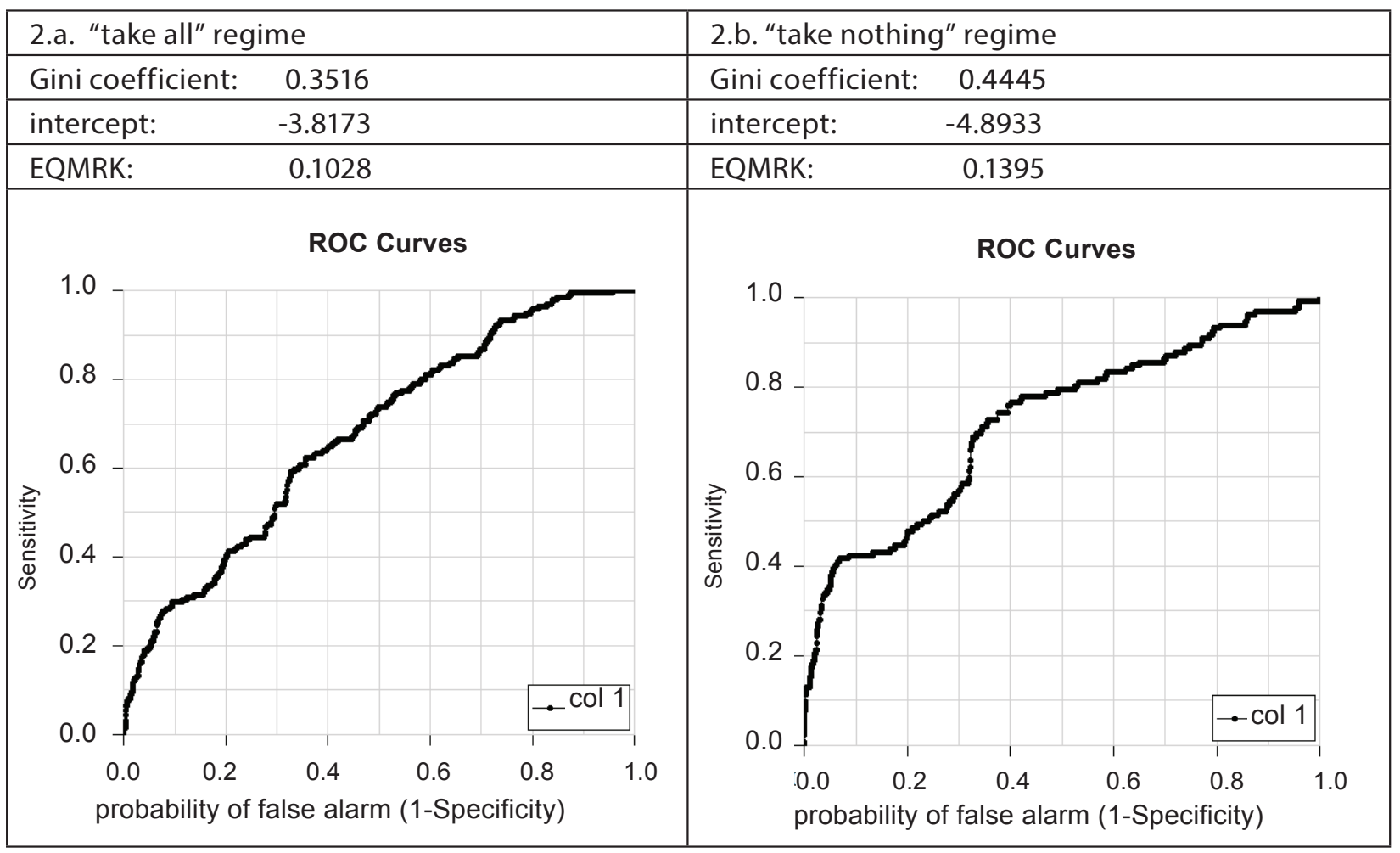

Source: the authors

\section{Outputs of Model 3}

\section{(explanatory variable: log return)}

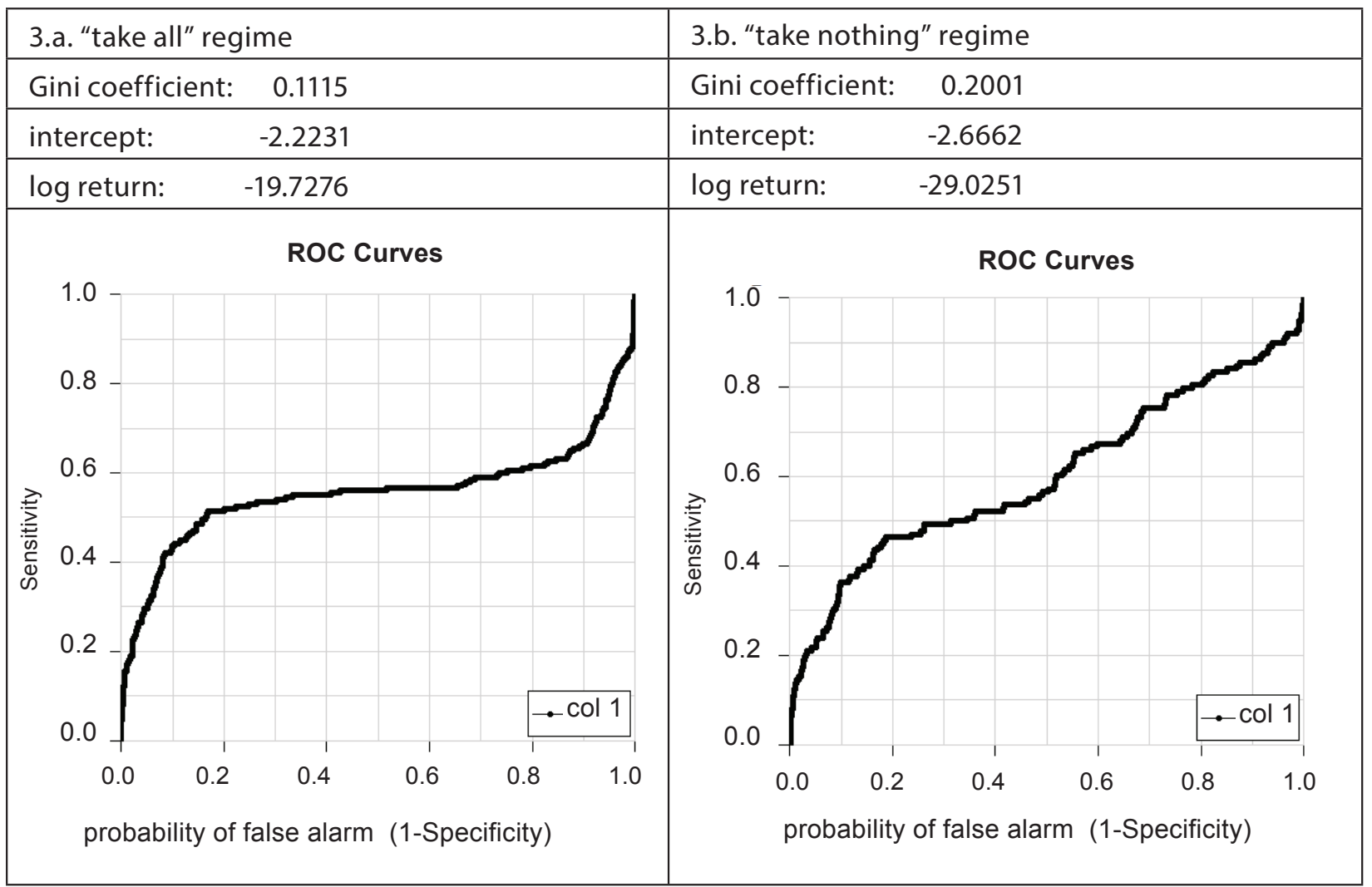

Source: the authors 


\section{Outputs of Model 4}

(explanatory variable: abs log return)

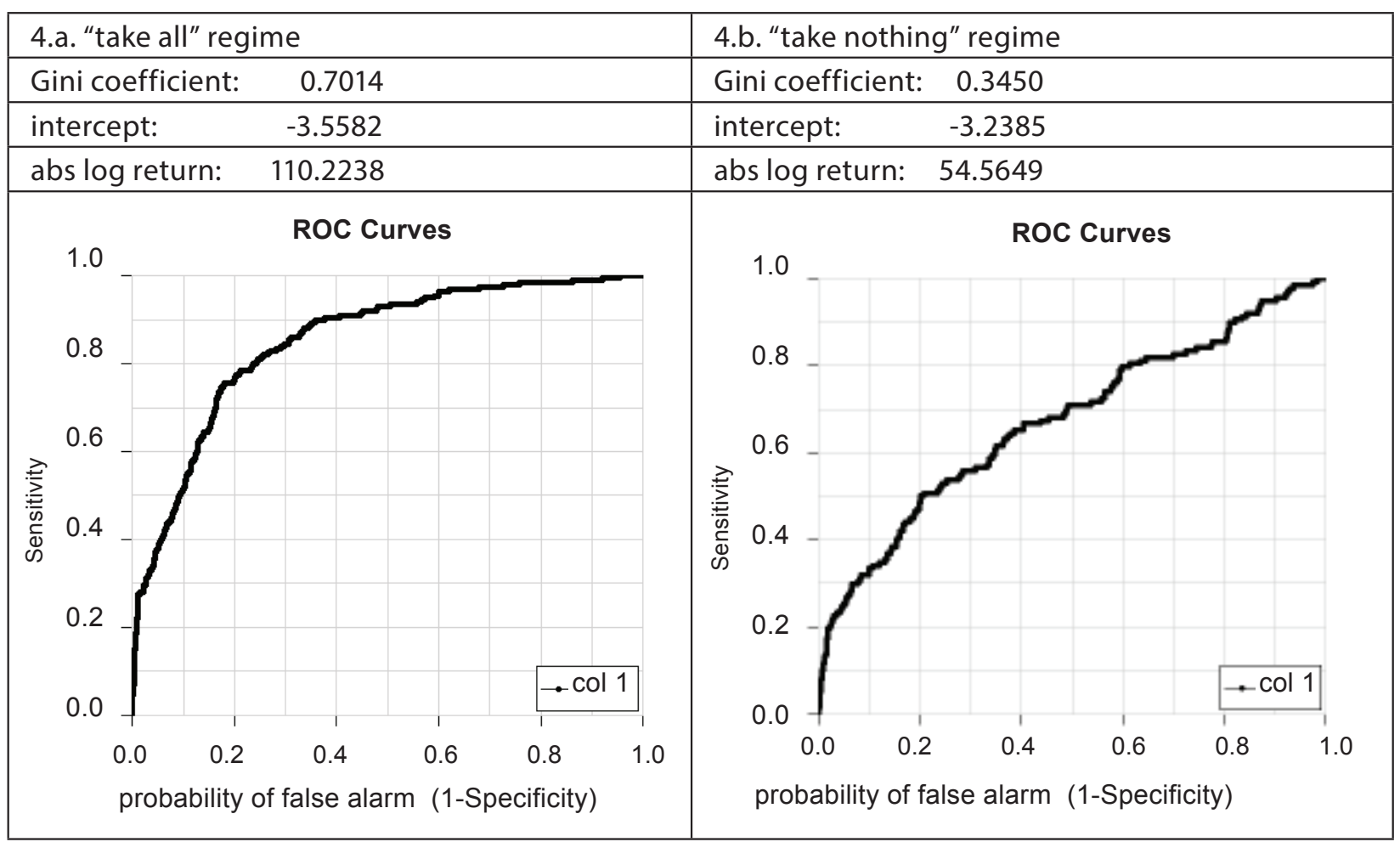

Source: the authors 


\section{Outputs of Model 5}

(explanatory variables: abs log return, VIX-index, Libor 3M, OIS, S\&P spread)

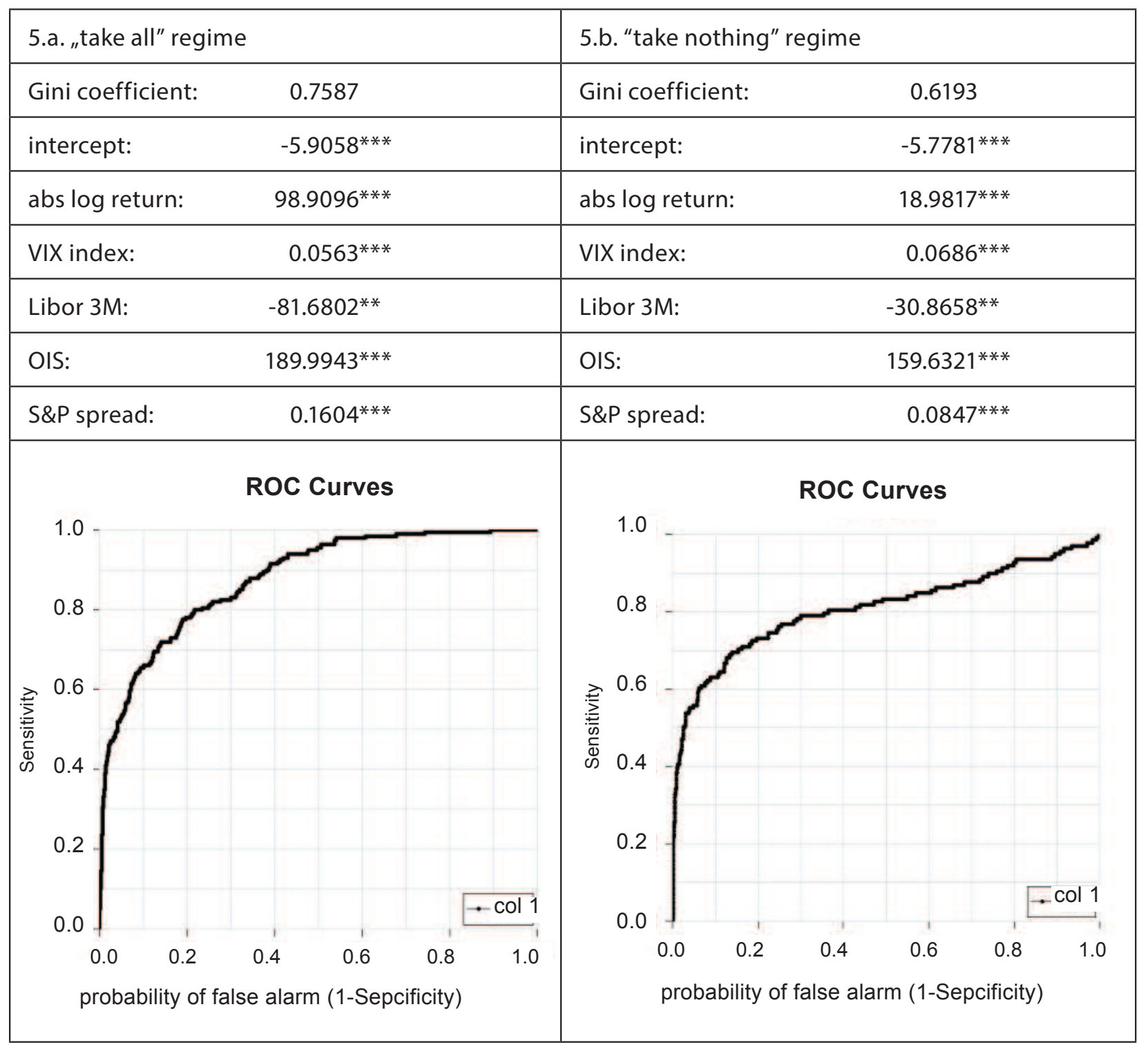

Source: the authors 